\title{
THE EFFECT OF GROWING MEDIA ON THE NUTRITIONAL VALUE OF CHERRY TOMATO
}

\author{
András Palkovics*, Csaba Szabó,, András László Kiss \\ Faculty of Horticulture and Rural Development, John von Neumann University \\ https://doi.org/10.47833/2020.2.AGR.019
}

\begin{abstract}
Keywords:
growing media

cherry tomato

nutritional value
\end{abstract}

\section{Article history:}

Received $\quad 10$ Feb 2020

Revised 13 March 2020

Accepted 20 March 2020

\begin{abstract}
The aim of this paper is to demonstrate how certain growing media (rockwool slab, coco slab, and coco substrate in window box) can change nutritional values of different tomato cultivars in hydroponic system. The test took place at the Study Garden of Faculty of Horticulture and Rural Development, John von Neumann University in the summer of 2018. The paper shows the role of growing media and particular tomato cultivars in the development of sensory and biochemical characteristics.
\end{abstract}

\section{Introduction}

The tomato crop (Solanum lycopersicum L.) has a great importance in the world. The tomato is classified as a functional food, for having good levels of vitamins, minerals, and especially lycopene, a carotenoid pigment that provides red color and has antioxidant qualities [1]. The lycopene content of tomato is also significant, which is an antioxidant dye belonging to the carotenoid family. Lycopene is responsible for the red color of tomato. The quality of tomato depends on the variety, the growing conditions, and the growing technology. To produce organic food, it is necessary to use inputs and methods that improve the ecological equilibrium of natural systems. Accordingly, organic vegetables are produced without fertilizers and genetically modified organisms, using only pesticides authorized in organic farming. The value of organic product consists of not only the product itself, but also the growing process [2]. The main incentives for buying organic food are the personal principles of consumers and their health concerns. So consumers take into consideration agricultural aspects as well as environmental and social factors.

\section{Material and method}

The test took place at the Study Garden of Faculty of Horticulture and Rural Development, John von Neumann University in the summer of 2018. The greenhouse has an automatic temperature control system and a ventilation system, and also a shading system, where experimental conditions are provided for growing. During the experiment we examined the changes in the nutritional value of three varieties of tomatoes (Luciplus F1, Summer sun F1, and Sir Elyan F1). The propagating material was provided by Alfa Lucullus Kft.

Luciplus $\mathrm{F} 1$ is an oval type, it has a good quality and very high yield. It produces well-colored, bright red fruits $\left(20 \mathrm{~g} / \mathrm{pcs}\right.$.), has an average Brix content of $7-8^{\circ}$ and has superb shelf life.

Summer sun $\mathrm{F} 1$ is an ever-growing variety. It has yellow fruits $(15-20 \mathrm{~g} / \mathrm{pcs}$.) with a diameter of 25-32 mm. It has powerful growth and high yield. Brix value 8-9 ${ }^{\circ} \mathrm{R}: \mathrm{Vd}$; Fol.1; ToMV.

Sir Elyan F1 is an ever-growing, San Marzano (elongated or Lucullus) variety. It has long (9$10 \mathrm{~cm})$, bright red fruits (100-130 g/pcs.) that are juicy, delicious, and long-lasting. It has high yield. HR: ToMV, V: 0, Fol: 0, 1, TSWV: 0. IR: M.

\footnotetext{
*Corresponding author. E-mail address: palkovics.andras@kvk.uni-neumann.hu
} 
We planted each of the tomato cultivars in three different growing media: rockwool slab, coco slab, and coco substrate in window box.

We planted 12-12 of each tomato varieties to all three growing media. The plants were supplied with water and nutrients by the ITU Mix Station 30 nutrient dissolving machine, all tomato varieties got the same amount and composition of nutrient solution at equivalent intervals.

We collected samples from the first, the second, and the third cluster ripening zone. The content of the samples was analyzed in the Soil and Plant Laboratory of John von Neumann University. We examined the Brix \% of the dry matter content of the varieties in the various growing media.

The results were summarized on table, displayed on chart, and evaluated using the SPSS statistical program. In addition, visual examinations were carried out to monitor the development and health of the plants.

\section{Results}

Based on the results of the experiment, it can be stated that the different growing media did not affect the Brix \%, but the difference between the varieties was well observed (Fig. 1).

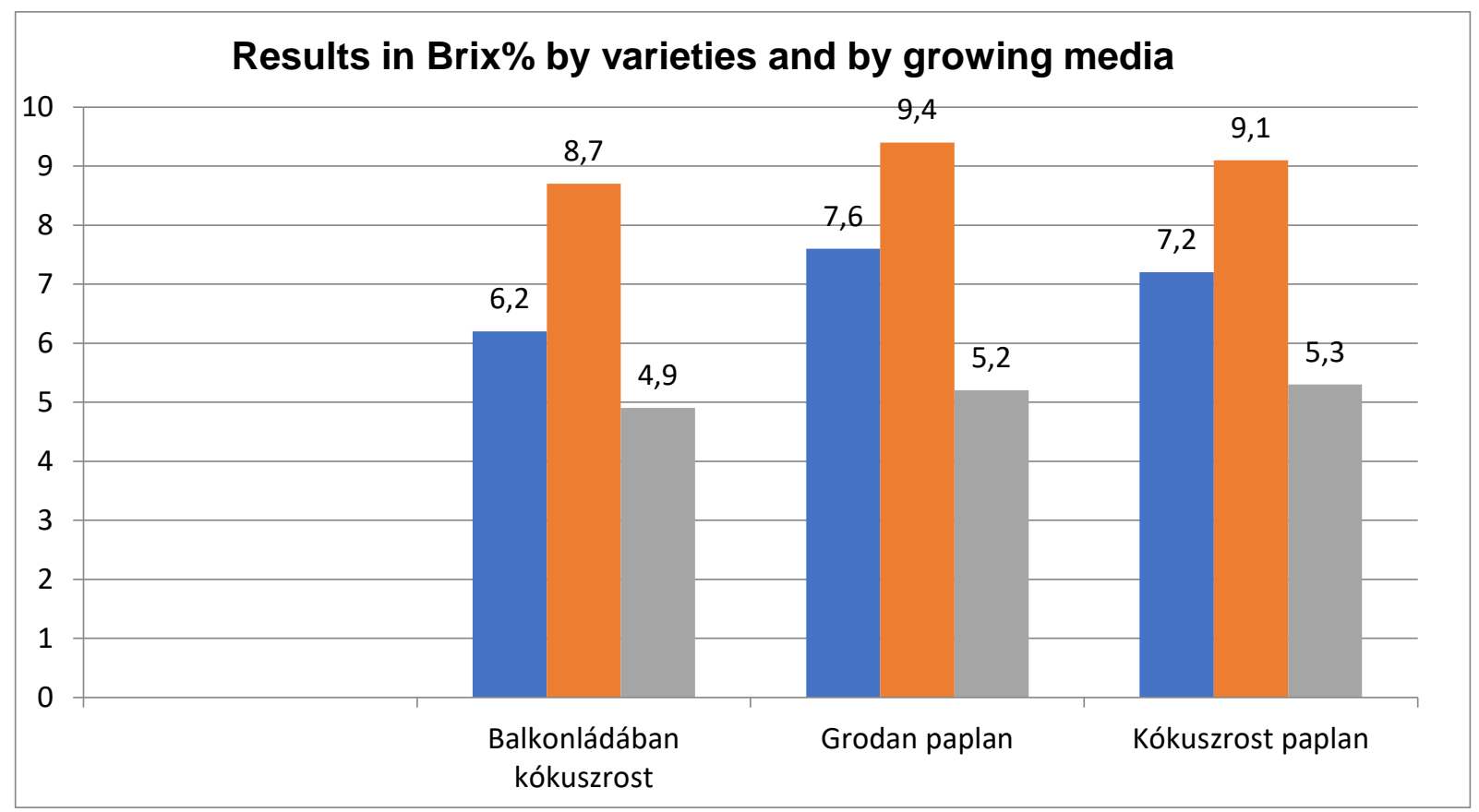

Fig. 1.: Brix \%: measured results by varieties and growing media (coco substrate in window box, rockwool slab, and coco slab)

The above statement also proved in the case of the dry matter content that there is no significant difference between the tomatoes grown in the same growing media, but the differences between the varieties can be clearly detected (Figure 2 ). 


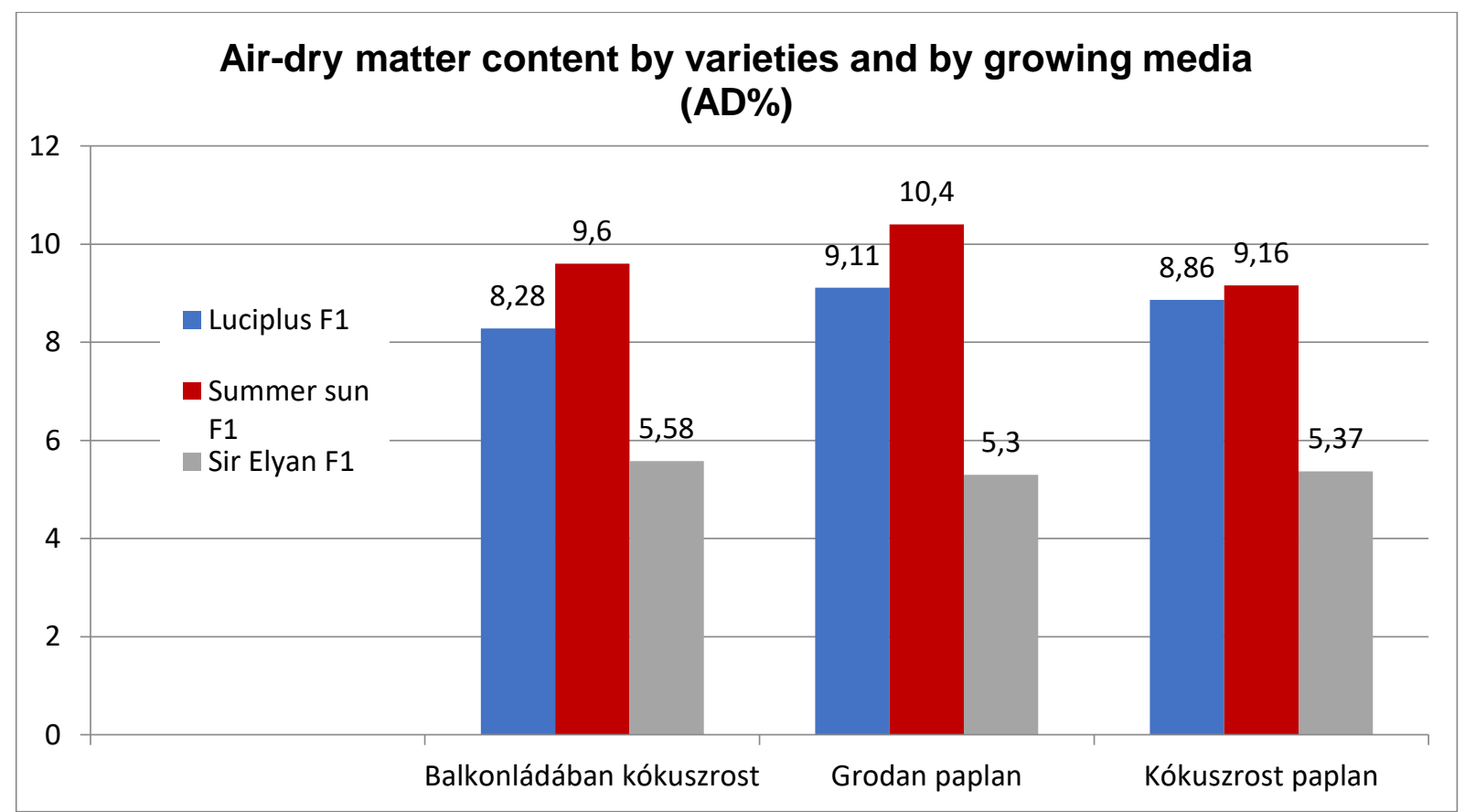

Fig. 2.: Air-dry matter content: measured results by varieties and growing media (coco substrate in window box, rockwool slab, and coco slab)

Examining the effect of the treatments, there was no statistically significant difference in the Brix $\%$ of the effect of the growing media on any of the tomato varieties.

The dry-matter content of tomatoes was not influenced by the different growing media in the examined varieties, and no significant difference could be detected in the dry-matter content of the fruits due to the growing media.

\section{Conclusions}

The paper shows that the particular tomato cultivars have an important role in the development of sensory and biochemical (nutritional value/dry-matter content) characteristics. Therefore, there is a need for purposefully selected cultivation technology and genotypes that respond favorably to organic farming in terms of organoleptic and biochemical properties and productivity. Moreover, we need evaluation of the cultivation system by collecting sample over a year.

There was no significant difference in dry-matter content and Brix \% of the tomato varieties grown in three different growing media. By visual inspection we can conclude that tomato plants grown on rock wool slab and coco slab developed more slowly, and in the case of Luciplus F1 and Sir Elyan F1 a peak appeared in the fruit due to relative calcium deficiency.

\section{Acknowledgement}

We are grateful for the support of the research that carried out in the framework of the EFOP3.6.2-16-2017-00012 "Developing functional, healthy and safe food product chain model from field to table in a thematic research network". The project is funded by the Hungarian State and the European Union, co-financed by the European Social Fund, and is part of the Széchenyi 2020 program.

\section{References}

[1] Tomato production in different growing media. [Online]. Available: https://www.ishs.org/ishs-article/178 14

[2] The growth and yield of cherry tomatoes in net covered greenhouses [Online]. Available: https://www.researchgate.net/publication/284315906 The growth and yield of cherry tomatoes in net covered greenhouses 